\title{
Effects of sessile Protozoa on intracapsular oxygen tension and embryonic shell calcification in the muricid Chorus giganteus
}

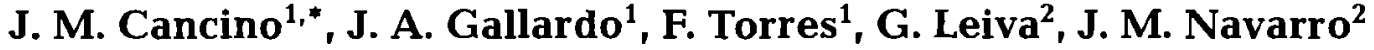 \\ ${ }^{1}$ Facultad de Ciencias, Universidad Católica de la Santísima Concepción, Casilla 297, Concepción, Chile \\ ${ }^{2}$ Instituto de Biología Marina, Universidad Austral de Chile, Casilla 567, Valdivia, Chile
}

\begin{abstract}
Clusters of egg capsules deposited by some common marine Mollusca may suffer problems of a low diffusive oxygen supply to the embryos they contain, especially if the capsules are exposed to hypoxic seawater or attachment and growth of marine biofouling organisms. The present study was undertaken to determine the effects of severe biofouling by sessile Protozoa on intracapsular oxygen tension $\left(\mathrm{IPO}_{2}\right)$ and the development of embryos contained in the egg capsules of the muricid snail Chorus giganteus. We also investigated the effects of ambient oxygen tension $\left(\mathrm{EPO}_{2}\right)$ on $\mathrm{IPO}_{2}$. The presence of sessile Protozoa attached to the outer wall of the egg capsules significantly reduced the $\mathrm{IPO}_{2}$ compared to capsules not fouled by Protozoa. Clean capsules containing embryos showed an $\mathrm{IPO}_{2}$ of about $105 \mathrm{~mm} \mathrm{Hg}$, compared with about $92 \mathrm{~mm} \mathrm{Hg}$ for protozoan-fouled capsules when both were immersed in air-saturated seawater at $12^{\circ} \mathrm{C}$. The embryos in capsules without Protozoa grew normally, hatching in about $70 \mathrm{~d}$ as veliconch larvae, whereas the development of larvae in protozoan-fouled capsules showed impairment of shell formation and delay in hatching for up to 5 mo. Pre-hatch embryos at $60 \mathrm{~d}$ measured about $922 \mu \mathrm{m}$ and had an ash content near $18 \mu \mathrm{g}$ embryo ${ }^{-1}$; embryos in capsules covered by micro-organisms measured only about $783 \mu \mathrm{m}$, with an ash content of about $3 \mu \mathrm{g}$ embryo ${ }^{-1}$ over the same time period. Our study suggested that the lack of larval calcification observed in the presence of sessile Protozoa on the outer wall of the egg capsules was probably related to reduced $\mathrm{IPO}_{2}$. Similarly, any factor reducing oxygen supply to encapsulated embryos (i.e. exposure to water masses with low oxygen content, biofouling, reduced water movement) could impair embryonic development, a significant phenomenon thus far not reported in C. giganteus.
\end{abstract}

KEY WORDS: Biofouling $\cdot$ Egg capsules $\cdot$ Mollusc $\cdot$ Embryonic development $\cdot$ Hypoxia

\section{INTRODUCTION}

Several recent papers have revealed striking changes in dissolved oxygen concentration within specific marine microhabitats, such as in tide pools and close to rocky substrata (Rosemberg \& Loo 1988, Shashar et al. 1993, Díaz \& Rosemberg 1995). As a consequence of such fluctuations, some organisms occurring close to the substratum may be exposed to extensive periods of hypoxia or even anoxia (Pihl et al. 1991). Many marine molluscs not only attach their eggs to the substratum but also lay them in clusters and in

•E-mail: jcancino@david.ucsc.cl large numbers enclosed in either egg masses or egg capsules (Gallardo 1981, Pechenik et al. 1984). The encapsulated development, common in some gastropods, suggests a priori that the contained embryos may be subjected to problems of oxygen supply, which may constrain both the shape of the capsules and the number of embryos they contain. Accordingly, Strathmann \& Strathmann (1995) have shown that the diffusive supply of oxygen is a limiting factor for embryos clustered in gelatinous egg masses. Development rate in 3 species of opisthobranch gastropods was retarded when exposed for 10 to $24 \mathrm{~h}$ to oxygen concentration below $10 \%$ air saturation. Some opisthobranch embryos exposed to low oxygen con- 
centration demonstrated a reduction in shell size at hatching. Moreover, supply of oxygen, rather than elimination of wastes, limited the rate of development within masses of aggregated embryos (Strathmann \& Strathmann 1995). The demand for oxygen could also explain why in Conus species the number of embryos increased in proportion to surface area of the capsule rather than to its volume (Perron \& Corpuz 1982). Similarly, in 3 species of gastropods the number of embryos decreased as the thickness of the egg mass increased (Lee \& Strathmann 1998). In an artificial gel matrix that simulated egg masses, development rate of central embryos became increasingly retarded in relation to peripheral embryos with increasing embryonic numbers and with increasing thickness of the gelatinous egg masses (Strathmann \& Strathmann 1989). Roller \& Stickle (1989) suggested that the relatively large number of veliger larvae inside egg capsules of Thais haemastoma caniliculata (Gray) might generate anaerobic stress that could influence the respiration rates of hatched larvae.

Recently, Cohen \& Strathmann (1996) tested the hypothesis that oxygen supply to embryos in egg masses might be affected by the thin layer of fouling micro-organisms covering the egg mass and demonstrated that photosynthesis and respiration of such micro-organisms affected the supply of oxygen to embryos within the mass. They also suggested that under certain conditions the oxygen supply could become a limiting factor for development, although we have not found any publication dealing with the longterm effects of a low oxygen supply on embryonic development related to the presence of bio-films on egg capsules. In intensive artificial culture of egg capsules of the Chilean muricid Chorus giganteus (Lesson, 1829), sessile Protozoa of the genera Tubilopora and Vorticella have been found to colonise the outer surfaces of egg capsules. This provided ideal material to experimentally evaluate the effects that a reduction in oxygen supply, due to the presence of fouling microorganisms, might have on intracapsular oxygen tension $\left(\mathrm{IPO}_{2}\right)$ levels and their consequences for embryonic development.

Chorus giganteus is an endemic muricid on the Chilean coast, occurring subtidally on soft sediments and in areas with small rocks (Gallardo 1981). Embryonic development occurs within egg capsules, from which lecithotrophic veliger larvae emerge in $70 \mathrm{~d}$ at $13^{\circ} \mathrm{C}$ (Leiva et al. 1998). It has been found that embryos subjected to hypoxic environmental conditions $(50 \%$ air saturation) developed more slowly, while shell formation and larval hatching from the capsule were prevented (J.M.C. et al. unpubl. data). The present study was undertaken to experimentally evaluate whether the presence of heavy protozoan fouling reduced oxy- gen tension within the egg capsules of $C$. giganteus and whether such a reduction in oxygen tension was associated with impaired development of intracapsular larvae.

\section{MATERIALS AND METHODS}

Experimental material. Egg capsules were obtained from a laboratory population of Chorus giganteus maintained in culture conditions at the Universidad Austral, Valdivia $\left(39^{\circ} 25^{\prime} \mathrm{S}, 73^{\circ} 10^{\prime} \mathrm{W}\right)$. About 100 capsules were harvested some 2 wk after oviposition and thoroughly washed with $5 \mu \mathrm{m}$ filtered seawater. About half of the capsules were maintained in clean glass aquaria in a constant flow of $5 \mu \mathrm{m}$ filtered seawater $\left(60 \mathrm{l} \mathrm{h}^{-1}\right)$ at $12 \pm 1^{\circ} \mathrm{C}$ and the remaining capsules were separately maintained in unfiltered seawater under similar conditions. Every 2 wk, 3 egg capsules were removed from each holding system and transported overnight to our laboratory in Concepción $\left(36^{\circ} 45^{\prime} \mathrm{S}\right.$; $73^{\circ} 10^{\prime} \mathrm{W}$ ) at $12^{\circ} \mathrm{C}$. Measurements included capsule length and surface area. Embryos were measured for length, total dry weight, and total organic and inorganic matter content.

Embryos were collected on pre-ashed fibreglass filters, washed in ammonium formate solution isotonic with seawater and dried to constant weight at $80^{\circ} \mathrm{C}$. Organic content was determined as the difference in dry mass before and after ashing for $4 \mathrm{~h}$ at $500^{\circ} \mathrm{C}$. Embryo length was measured using an ocular micrometer with a light microscope. The surface area of individual capsules was determined by cutting the capsule into 2 pieces along its longest axis and drawing both pieces on an acetate slide. The drawing was cut out and weighed and converted to surface area by dividing by the weight of a known area of acetate slide.

Capsules were maintained until hatching occurred in order to obtain measurements throughout the entire capsular growth phase and to compare data obtained using clean (W/OP) egg capsules with those from protozoan-fouled (WP) egg capsules.

Oxygen tension. Oxygen measurements (Fig. 1) were carried out using a Strathkelvin Model 781 oxygen meter fitted with a 1302 SI Strathkelvin electrode to determine ambient oxygen tension $\left(\mathrm{EPO}_{2}\right)$ and a Clark-type model 768-20R needle microelectrode (Diamond General Development Co., diameter $890 \mu \mathrm{m}$ ) to determine intracapsular oxygen tension $\left(\mathrm{IPO}_{2}\right)$. Both electrodes were calibrated using nitrogen-purged, oxygen-free seawater to produce a zero value of oxygen tension $\left(\mathrm{PO}_{2}\right)$ and $100 \%$ air-saturated seawater (6.24 $\mathrm{ml} \mathrm{O}_{2} \mathrm{l}^{-1}$ at $12^{\circ} \mathrm{C}$ and $30 \%$ salinity) to give a $\mathrm{PO}_{2}$ of $157 \mathrm{~mm} \mathrm{Hg}$. Measurements included the simultaneous evaluation of $\mathrm{EPO}_{2}$ and $\mathrm{IPO}_{2}$ first on W/OP egg 


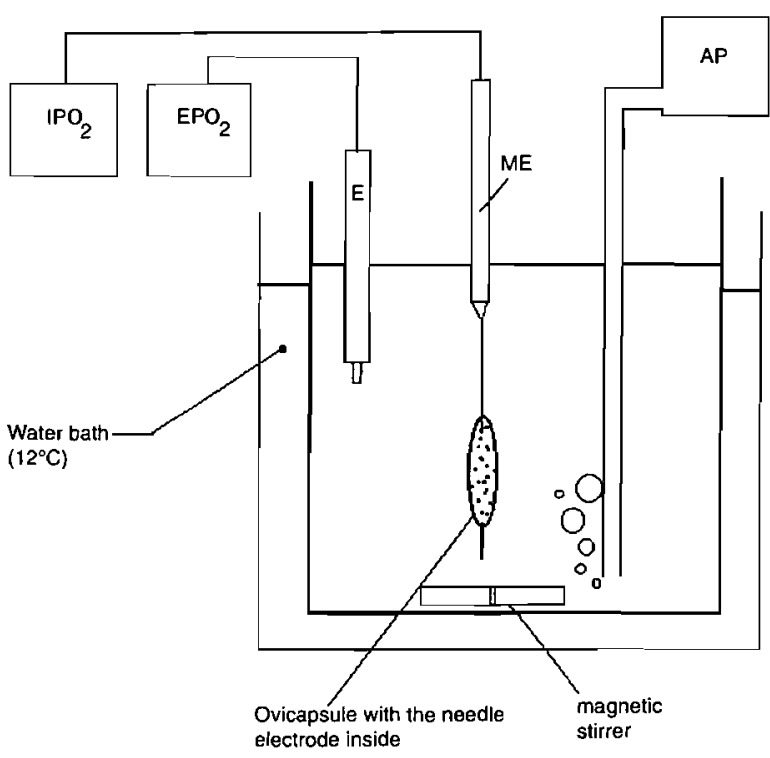

Fig. 1. Experimental set-up used for studying the intracapsular oxygen tension $\left(\mathrm{IPO}_{2}\right)$ in ovicapsules of Chorus giganteus. For measurements a single ovicapsule was immersed in $0.45 \mu \mathrm{m}$ filtered seawater. AP: air pump, E: electrode, $\mathrm{ME}$ : microelectrode, $\mathrm{EPO}_{2}$ : ambient oxygen tension

capsules and then on WP capsules. Three replicate measurements were made on each capsule type. Egg capsules were monitored individually in 11 beakers beginning with air-saturated $0.45 \mu \mathrm{m}$ filtered seawater at $12^{\circ} \mathrm{C}$ in a constant temperature bath. Water around the capsules was mechanically stirred during the measurement process. For $\mathrm{IPO}_{2}$ measurements, the microelectrode was inserted into the capsule after removal of the operculum, taking care not to allow the escape of embryos. Measurements of $\mathrm{IPO}_{2}$ and $\mathrm{EPO}_{2}$ were made over $30 \mathrm{~min}$ intervals in seawater at a $\mathrm{PO}_{2}$ of $157 \mathrm{~mm} \mathrm{Hg}$, and then at a $\mathrm{PO}_{2}$ of $78.5 \mathrm{~mm} \mathrm{Hg}$ (achieved by bubbling with $\mathrm{N}_{2}$ ). These readings were then repeated on empty capsules to test for sensitivity of the measurements, verifying that the noise level of the microelectrode was sufficiently low as not to interfere with the accuracy of the $\mathrm{PO}_{2}$ measurements.

A second set of measurements was made to determine the oxygen tension in clean and protozoan-fouled empty egg capsules.

The statistical significance of the effect of Protozoa on $\mathrm{IPO}_{2}$ was determined using 1-way analysis of variance (ANOVA). The effects of Protozoa on embryonic size were evaluated using a Kolmogorov-Smirnov (K-S) test on the size-frequency distribution. The effects of environmental oxygen and presence or absence of embryos in egg capsules on $\mathrm{IPO}_{2}$ were tested using 1-way ANOVA.

\section{RESULTS}

\section{Oxygen tension}

Fig. 2 demonstrates the variation of oxygen measurements inside egg capsules with and without embryos, under 2 regimes of $\mathrm{EPO}_{2}$. The $\mathrm{IPO}_{2}$ of the egg capsules was well below the $\mathrm{EPO}_{2}$, and when transferred to ambient water with a different $\mathrm{EPO}_{2}$, the $\mathrm{IPO}_{2}$ value stabilised after a lag time of about 15 to $30 \mathrm{~min}$ to a lower-than-ambient value. Egg capsules containing embryos showed an internal depletion of about $25 \%$ saturation when immersed in seawater with a $\mathrm{PO}_{2}$ of $157 \mathrm{~mm} \mathrm{Hg}$ and about the same percentage of further depletion when transferred to seawater with a $\mathrm{PO}_{2}$ of $78.5 \mathrm{~mm} \mathrm{Hg}$. The IPO $\mathrm{I}_{2}$ of empty capsules differed only slightly from the $\mathrm{EPO}_{2}$ and even this difference may have resulted from error incurred when using the Clark electrode. Based on the results of Fig. 2, measurements of $\mathrm{IPO}_{2}$ were only recorded $30 \mathrm{~min}$ after immersion of the egg capsules in test seawater.

\section{Effect of protozoan fouling on oxygen tension}

Fig. 3 shows the differences in $\mathrm{IPO}_{2}$ between WP and W/OP egg capsules, both with and without the presence of embryos in the capsules. The differences observed in $\mathrm{IPO}_{2}$ between WP and W/OP egg capsules in the presence of embryos were statistically significant $\left(\mathrm{ANOVA} ; F_{(1,4)}=9.83, \mathrm{p}<0.05\right)$. Significant differences in $\mathrm{IPO}_{2}$ between WP and W/OP egg capsules persisted when embryos were absent from the capsules (Fig. 3, 'no embryos') $\left(\right.$ ANOVA $_{i} F_{(1,4)}=15.0$,

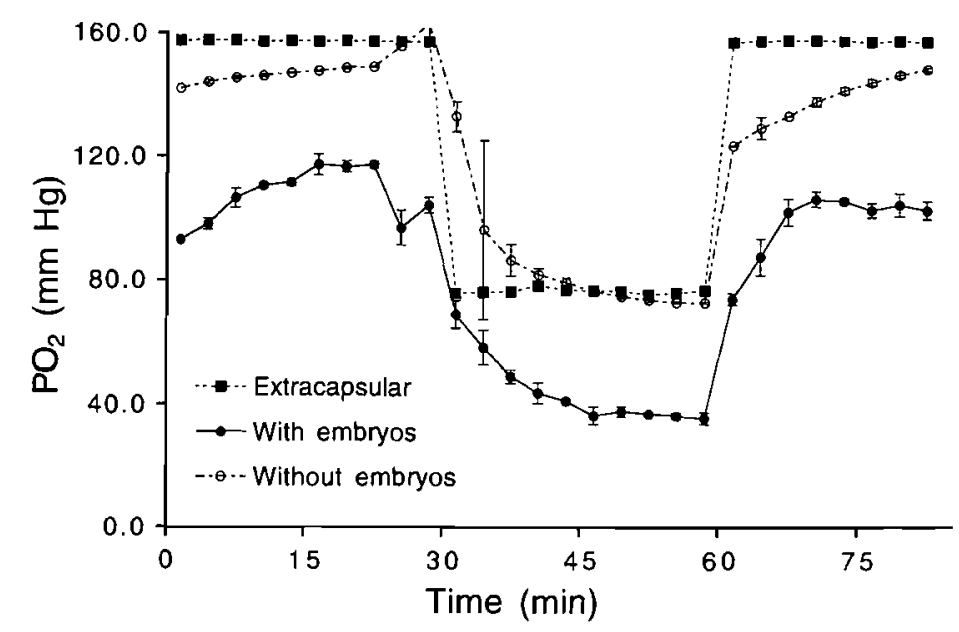

Fig. 2. Chorus giganteus. Responses of intracapsular oxygen tension $\left(\mathrm{IPO}_{2}\right)$ to changes in the ambient oxygen tension $\left(\mathrm{EPO}_{2}\right)$ of water in which the egg capsules were immersed.Values are average \pm 1 SD $(\mathrm{n}=3)$ 


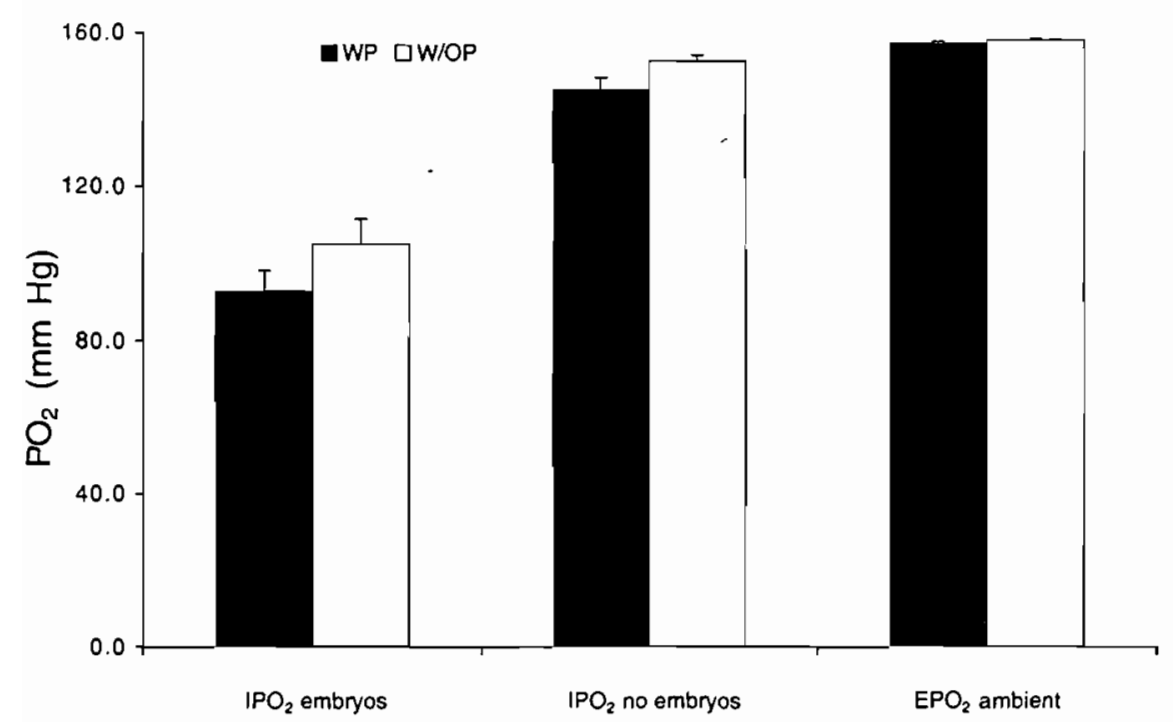

Fig. 3. Chorus giganteus. Intracapsular oxygen saturation $\left(\mathrm{IPO}_{2}\right)$ in egg capsules with and without pre-hatching embryos (60 d) in clean (W/OP) and protozoanfouled (WP) egg capsules, compared with ambient oxygen tension $\left(\mathrm{EPO}_{2}\right)$. Values are average $+1 \mathrm{SD}(\mathrm{n}=3)$

$\mathrm{p}<0.05$ ); but the overall values in $\mathrm{PO}_{2}$ were near the external $157 \mathrm{~mm} \mathrm{Hg}$ saturation value (clean $\cong 152 \mathrm{~mm}$ $\mathrm{Hg}$, protozoan $\cong 145.5 \mathrm{~mm} \mathrm{Hg}$ ). The 'no embryos' $\mathrm{IPO}_{2}$ values (Fig. 3) were significantly different from the $\mathrm{EPO}_{2}$ values (ANOVA; $F_{(1,4)}=27.7, \mathrm{p}<0.05$ ), suggesting that either the wall of the capsule acted as a barrier to oxygen diffusion or the electrode consumption was enough to produce a slight drop in oxygen tension below the external value.

\section{Effect of protozoan fouling on embryonic development}

Egg capsules maintained in filtered water remained clean and underwent normal development, with larvae beginning to emerge at $70 \mathrm{~d}$. Within $30 \mathrm{~d}$, capsules maintained in non-filtered seawater had acquired a covering of Protozoa including mainly Vorticella and Tubilopora spp. Embryos within these capsules developed into larvae bearing a normal foot, velum and operculum, but lacking a shell (protoconch). Embryos in this condition failed to emerge, even after $5 \mathrm{mo}$ in culture. Size-frequency distribution of embryos (Fig. 4) was significantly different between those from clean and those from protozoan-covered capsules (K-S test; $\chi^{2}=64.071 ; \mathrm{df}=2$; $\mathrm{p}<0.05 ; D_{\max }=0.566$ ). W/OP egg capsules produced pre-hatching embryos with an average length of $922 \pm 84 \mu \mathrm{m}$, while those from WP egg capsules measured $783 \pm 78 \mu \mathrm{m}$ in the same time period. Embryos from WP egg capsules were significantly lighter in total dry weight than those from clean capsules (ANOVA; $F_{(1,4)}=19.8, p<0.05$ ), as shown in Fig. 5. In W/OP egg capsules, individual dry weights of the embryos increased rapidly over the first $15 \mathrm{~d}$ of culture due to their consumption of nurse eggs, thereafter decreasing until Day 45. Dry weight then

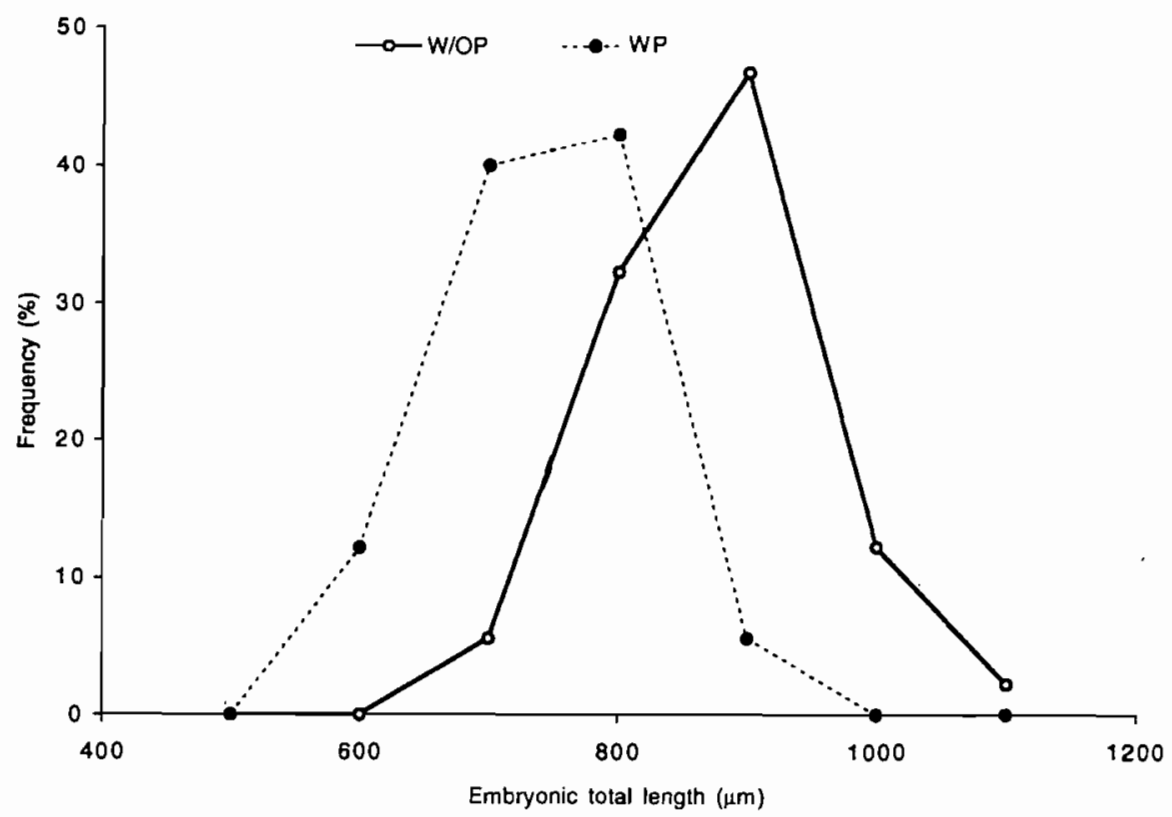

Fig. 4. Chorus giganteus. Size-frequency distribution of pre-hatching embryos (60 d) from clean (W/OP) and protozoan-fouled (WP) egg capsules 


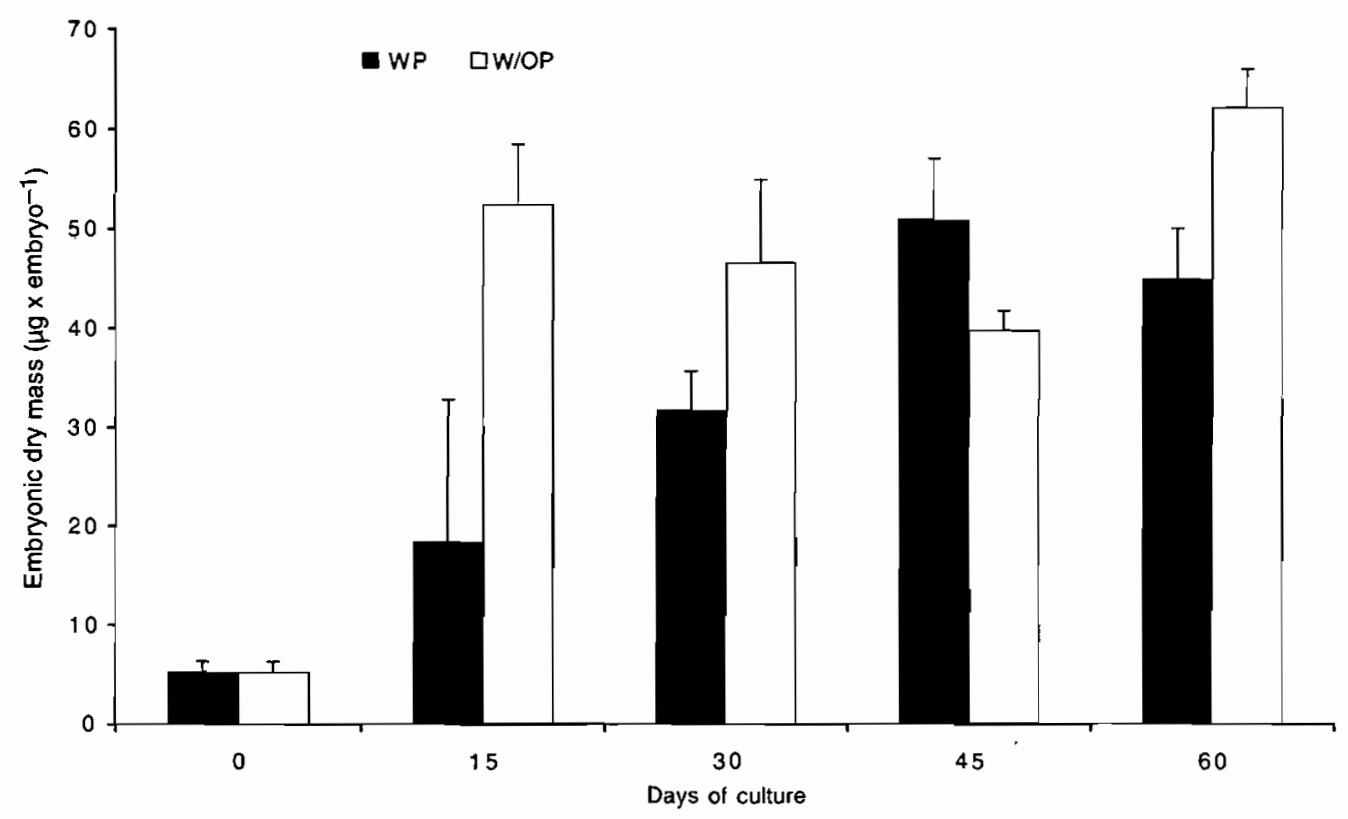

Fig. 5. Chorus giganteus. Total dry weight of embryos in clean (W/OP) and protozoan-fouled (WP) egg capsules as a function of time in culture. Values are averages + 1 SD $(n=3)$

increased towards Day 60 due to shell deposition. Embryos from WP egg capsules grew more slowly than the non-fouled group until Day 45, thereafter showing a decline towards Day 60, probably due to lack of shell deposition. Organic matter content (AFDW [ash-free dry weight]) per embryo also varied over the culture period, in a manner similar to, but more pronounced than, the values for total dry mass (Fig. 6). However, after $60 \mathrm{~d}$ there was no statistical difference between the 2 groups (ANOVA $F_{(1,4)}=0.42, p=0.54$ ). Embryonic inorganic matter did not vary significantly between clean and protozoan-fouled groups until Day 45

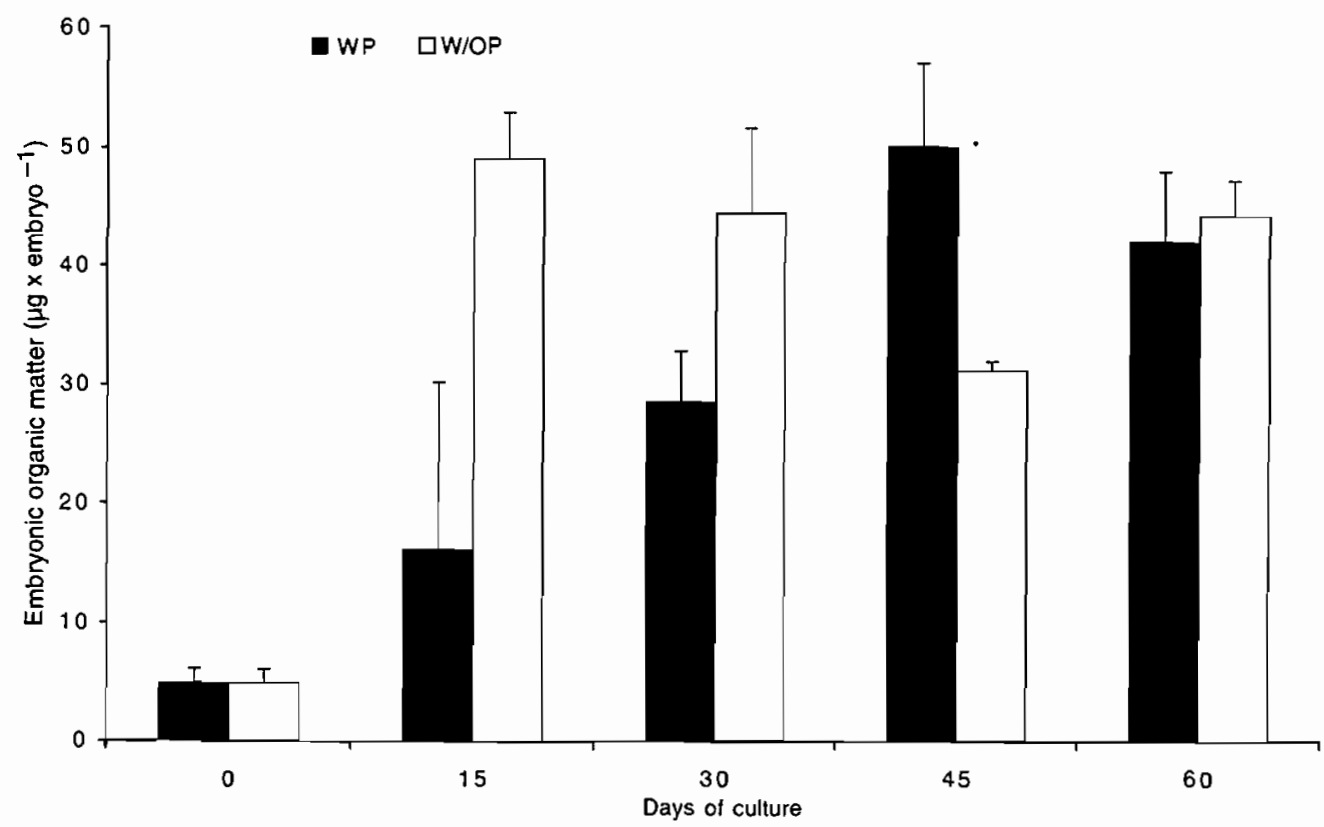

Fig. 6. Chorus giganteus. Organic matter (AFDW) of embryos in clean (W/OP) and protozoan-fouled (WP) egg-capsules as a function of time in culture. Values are averages +1 SD $(n=3)$ 


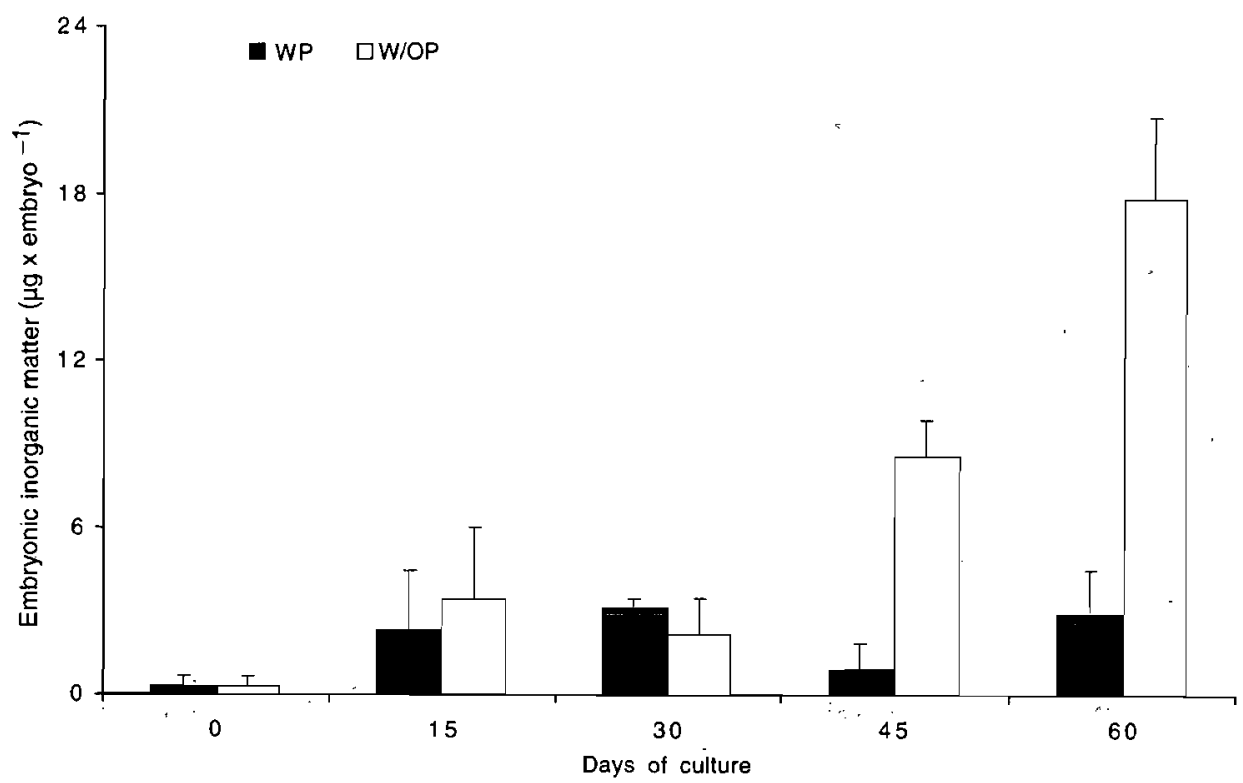

Fig. 7. Chorus giganteus. Inorganic content (ash weight) of embryos in clean (W/OP) and protozoan-fouled (WP) egg capsules as a function of time in culture. Values are averages +1 SD $(n=3)$

(Fig. 7), at which time they began to diverge sharply due to shell deposition in embryos of the clean-capsule group (ANOVA; $F_{(1,4)}=42.7, \mathrm{p}<0.05$ ). The average surface area of individual W/OP and WP egg capsules were not significantly different (Table 1) (ANOVA; $\left.F_{(1,4)}=0.06, p=0.80\right)$. However, the number of embryos present in each type of capsule at Day 60 was significantly lower in W/OP than in WP egg capsules (Table 1) (ANOVA; $F_{(1,4)}=18, p<0.05$ ), suggesting that the presence of biofouling affected nurse eggs consumption.

Table 1. Number of embryos and surface area of clean (W/OP) and protozoan-fouled (WP) egg capsules. Values are averages $\pm \mathrm{SD}$

\begin{tabular}{|lcc|}
\hline & No. of embryos & Surface area $\left(\mathrm{cm}^{2}\right)$ \\
\hline Without Protozoa & $120 \pm 9$ & $2.44 \pm 0.07$ \\
With Protozoa & $174 \pm 21$ & $2.42 \pm 0.11$ \\
\hline
\end{tabular}

\section{DISCUSSION}

The present study has shown that a certain degree of oxygen depletion occurred within egg capsules of developing Chorus giganteus embryos relative to the $\mathrm{PO}_{2}$ values of the ambient seawater and that these values were depressed significantly further when the egg capsules were fouled with a covering of sessile Protozoa. It was simultaneously observed that there was an impairment of development of embryos contained within WP egg capsules when compared with W/OP egg capsules held under the same conditions.

Several studies on different animals have reported retarded development of embryos located in the centre of egg masses and have suggested that oxygen supply could be the limiting factor (Chaffee \& Strathmann 1984, Lucas \& Crisp 1987, Seymour \& Roberts 1991, Strathmann \& Strathmann 1995, Cohen \& Strathmann 1996). Such information has led to the conclusion that in many cases encapsulated embryos could be developing at the limit of their tolerance to hypoxia (Cohen \& Strathmann 1996). The rate of oxygen supply by diffusion has been regarded as one of the factors that regulate, through natural selection, the density of embryos within such masses. The shape and size of egg masses may even influence the dispersal strategies used by different organisms (Perron \& Corpuz 1982, Roller \& Stickle 1989, Strathmann \& Strathmann 1989, 1995, Lee \& Strathmann 1998). Recently, Cohen \& Strathmann (1996) showed that the supply of oxygen to embryos of marine invertebrates is also affected by the film of micro-organisms that usually covers the egg masses. The internal oxygen tension becomes dependent on light intensity, since bacteria and micro-algae in such films contribute oxygen in the daytime, increasing the oxygen diffusion gradient across the egg capsule, while at night the oxygen tension gradient will be decreased due to microbial respiration (Cohen \& Strathmann 1996), In the present study we did not determine the effect of light on $\mathrm{IPO}_{2}$. Moreover, we did 
not determine if the microbial film increased diffusion distances across the egg capsule. Micro-algae or bacteria, if present, were not as conspicuous as the sessile Piotozoa.

It appeared that Chorus giganteus egg capsules fouled by sessile Protozoa received insufficient oxygen for normal development of the encapsulated embryos. Biofouling was correlated with a lower $\mathrm{IPO}_{2}$ level and a higher oxygen demand due to an increase in the number of embryos (Table 1). This elevation in embryo number probably resulted from reduced nurse-egg consumption, through lower developmental rate generated by a lower oxygen supply. Thus, embryonic weight increased faster during early development within W/OP egg capsules than in WP ones (Figs. 5 \& $6)$, suggesting that the embryos in the former condition consumed a higher number of nurse eggs and sibling embryos than those in WP egg capsules. Higher nurseegg consumption would have left a lower number of embryos for further development in W/OP egg capsules.

Although the factors interfering with oxygen diffusion across the egg capsule could also impair nitrogenous waste disposal, based on evidence from the literature, we hypothesise that the effects detected on shell calcification are due to low oxygen tension rather than to increased nitrogenous concentration. Strathmann \& Strathmann (1995) reported, for example, that exposure of egg masses of opisthobranchs to a low oxygen supply interfered with shell formation, generating individuals with shorter shells. Baker \& Mann (1994) reported that larvae of Crassostrea virginica failed to develop the protoconch when reared in seawater with an oxygen content below $1 \%$ saturation; similarly. embryos of Chorus giganteus did not produce a protoconch if reared in seawater with an oxygen content of $3.12 \mathrm{ml} \mathrm{O}_{2} \mathrm{l}^{-1}$ (J.M.C. et al. unpubl. data).

The lack of shell calcification could arise for 2 reasons involving oxygen tension. First, if anaerobic metabolic pathways are used under hypoxic conditions, this could produce acidic end-products, which could be partially compensated by mobilisation of $\mathrm{CaCO}_{3}$, so detracting from calcification (De Zwaan 1983). Second, if the intracapsular fluid became acidic, it might prevent the utilisation of carbonates for shell formation, since at a low $\mathrm{pH}$ level the balance of the carbonate equation would be displaced towards carbon dioxide and carbonic acid rather than towards carbonates. The control of blood acid-base balance in the long term may have more to do with regulating shell depositionabsorption and maintaining $\mathrm{Ca}^{2+}$ and $\mathrm{HCO}_{3}^{-}$levels than with maintaining short-term extracellular homeostasis (Byrne \& Dietz 1997). The gills and shell are the primary sites of calcium regulation in relation to the external environment (Silverman et al. 1987). How- ever, in the gills calcium is present as calcium phosphate, which is less soluble than calcium carbonate present in the shell. Therefore, the calcium in the shell is more accessible as a source of calcium and bicarbonate to aid in acid-base regulation (Cameron 1990).

The high sensitivity of intracapsular development to low oxygen supply in Chorus giganteus is unusual, as the species lives subtidally in areas with soft sediments where the water movement is low. In such an environment, oxygen supply is likely to be limiting near the water-substratum boundary layer where capsules of $C$. giganteus are attached in clusters to small rocks $(\mathrm{Gal}-$ lardo, 1981). Furthermore, within the distributional range known for this snail (Antofagasta $\left[23^{\circ} 48^{\prime} \mathrm{S}\right.$, $\left.70^{\circ} 32^{\prime} \mathrm{W}\right]$ to Valdivia $\left[39^{\circ} 25^{\prime} \mathrm{S}, 73^{\circ} 10^{\prime} \mathrm{W}\right.$; Osorio et al. 1979) the species is likely to encounter seawater with very low values of oxygen content. In the area near Concepción in central Chile, for example, where natural populations of the snails occur at present, oxygen values as low as $1.2 \mathrm{ml} \mathrm{O}_{2} \mathrm{I}^{-1}$ have been reported to last for several months in spring time (Ahumada 1976, 1994, Llancamil 1982). Based on the present information we suggest that under such conditions the embryonic development of $C$. giganteus should be impaired by low oxygen supply to their embryos.

Acknowledgements. This research was financed by the 'Programa Acuicultura y Biotecnología Marina, 1(97), FONDAP, Chile (subprograma invertebrados)'. The manuscript was greatly improved thanks to suggestions by 2 anonymous referees.

\section{LITERATURE CITED}

Ahumada R (1976) Contribución al conocimiento de las condiciones hidrográficas de la Bahía de Concepción y áreas adyacentes (Chile). Tesis de Licenciatura, Universidad de Concepción

Ahumada R (1994) Condiciones oceanográficas del Golfo de Arauco y Bahías adyacentes. In: Della Croce N (ed) El Río Biobío y el Area Marina Adyacente, Chile Central (Contribuciones) N. Serie monografías científicas. Universidad de Genova, p 5-39

Baker S, Mann R (1994) Description of metamorphic phases in the oyster Crassostrea virginica and effects of hypoxia on metamorphosis. Mar Ecol Prog Ser 104:91-99

Byrne R, Dietz T (1997) Ion transport and acid-base balance in freshwater bivalves. J Exp Biol 200:457-465

Cameron $\mathbf{J}(1990)$ Unusual aspects of calcium metabolism in aquatic animals. Annu Rev Physiol 52:77-95

Chaffee C, Strathmann R (1984) Constraints on egg masses. 1. Retarded development within thick egg masses. J Exp Mar Biol Ecol 84:73-83

Cohen C, Strathmann R (1996) Embryos at the edge of tolerance: effects of environment and structure of egg masses on supply of oxygen to embryos. Biol Bull 190:8-15

De Zwaan A (1983) Carbohydrate catabolism in bivalves. In: Hochachka PH (ed) The Mollusca, Vol 1. Academic Press, New York, p 137-169

Díaz R, Rosemberg R (1995) Marine benthic hypoxia: a review 
of its ecological effects and the behaviour responses of benthic macrofauna. Oceanogr Mar Biol Annu Rev 33: $245-303$

Gallardo C (1981) Posturas y estadios de eclosión del gastrópodo muricidae Chorus giganteus (Lesson, 1829). Stud Neotrop Fauna Environ 16:35-44

Lee CE, Strathmann RR (1998) Scaling of gelatinous clutches: effects of siblings' competition for oxygen on clutch size and parental investment per offspring. Am Nat 151: 293-310

Leiva GE, Muñoz JE, Navarro JM (1998) Desarrollo intracapsular y mecanismos de eclosión del caracol trumulco Chorus giganteus (Lesson, 1829) (Gastropoda: Muricidae), bajo condiciones de laboratorio. Rev Chil Hist Nat 71: $157-167$

Llancamil LA (1982) Variación estacional invierno primavera de la temperatura, salinidad y oxígeno en Bahía Coliumo $\left(36^{\circ} 32^{\prime} \mathrm{S} ; 72^{\circ} 57^{\prime} \mathrm{W}\right)$. Tesis de Licenciatura, Universidad de Concepción

Lucas M, Crisp D (1987) Energy metabolism of eggs during embryogenesis in Balanus balanoides. J Mar Biol Assoc UK 67:27-54

Osorio C, Atria J, Mann S (1979) Moluscos marinos de importancia económica en Chile. Biol Pesq 11:3-47

Pechenik JA, Chang SC, Lord A (1984) Encapsulated development of marine prosobranch gastropod Nucella lapillus. Mar Biol 78:223-229

Perron FE, Corpuz GC (1982) Costs of parental care in the gastropod Conus pennaceus: age specific changes and physical constraints. Oecologia 55:319-324

Editorial responsibility: Roger Hughes (Contributing Editor), Bangor, United Kingdom
Pihl L, Baden SP, Díaz RJ (1991) Effects of periodic hypoxia on distribution of demersal fish and crustaceans. Mar Biol 108:349-360

Roller $R_{1}$ Stickle W (1989) Temperature and salinity effects on the intracapsular development, metabolic rates, and survival to hatching of Thais haemastoma caniliculata (Gray) (Prosobranchia: Muricidae) under laboratory conditions. J Exp Mar Biol Ecol 125:235-251

Rosemberg R, 'Loo L (1988) Marine eutrophication induced oxygen deficiency: effects on soft bottom fauna, Western Sweden. Ophelia 29:213-225

Seymour R, Roberts J (1991) Embryonic respiration and oxygen distribution in foamy and non foamy egg masses of the frog Limnodynastes tasmaniensis. Physiol Zool 64: $1322-1340$

Shashar N, Cohen Y, Loya Y (1993) Extreme diel fluctuations of oxygen in diffusive boundary layers surrounding stony corals. Biol Bull 185:455-461

Silverman H, Kays H, Dietz T (1987) Maternal calcium contribution to glochidial shells in freshwater mussels (Eulamellibranchia: Unionidae). J Exp Zool 242:137-146

Strathmann RR, Strathmann MF (1989) Evolutionary opportunities and constraints demonstrated by artificial gelatinous egg masses. In: Ryland JS, Tyler PA (eds) Reproduction, genetics and distribution of marine organisms. Olsen and Olsen, Fredensborg, p 201-209

Strathmann RR, Strathmann MF (1995) Oxygen supply and limits on aggregation of embryos. J Mar Biol Assoc UK $75: 413-428$

Submitted: October 1, 1999, Accepted: December 20, 1999 Proofs received from author(s): June 13,2000 